\title{
Composição química da silagem de sorgo forrageiro em função da frequência de
}

\section{corte}

\author{
Chemical composition of forage sorghum silage as a function of cutting frequency \\ Composición química del ensilaje de sorgo forrajero en función de la frecuencia de corte
}

Recebido: 13/10/2021 | Revisado: 18/10/2021 | Aceito: 19/10/2021 | Publicado: 21/10/2021

Haroldo Wilson da Silva
ORCID: https://orcid.org/0000-0003-2360-8599
Universidade Estadual Paulista “Júlio de Mesquita Filho”, Brasil
E-mail: haroldowsilva@gmail.com
Arleto Tenório dos Santos
ORCID: https://orcid.org/0000-0002-0353-3609
Escola Prof. Dr. Antônio Eufrásio de Toledo, Brasil
E-mail: arletotenorio@ @ahoo.com.br
Pierro Eduardo Perego
ORCID: https://orcid.org/0000-0001-6054-9714
Escola Prof. Dr. Antônio Eufrásio de Toledo, Brasil
E-mail: pirroperego@gmail.com
Angela Madalena Marchizelli Godinho
ORCID: https://orcid.org/0000-0001-5376-6681
Faculdade de Tecnologia de São Paulo, Brasil
E-mail: angela.godinho@ fatec.sp.gov.br

\begin{abstract}
Resumo
Objetivou-se avaliar as características químicas da silagem de sorgo forrageiro em diferentes frequências de corte. A pesquisa foi conduzida no setor experimental na Faculdade de Tecnologia de São Paulo nas dependências da FATEC de Presidente Prudente-SP. Utilizou-se a variedade de sorgo forrageiro (Híbrido silageiro Podium safra 2019 Biomatrix). O delineamento experimental utilizado foi em blocos ao acaso, com três parcelas subdivididas, com quatro repetições. Os tratamentos foram: T1 - APIC - antes do ponto ideal de corte; T2 - PIC - ponto ideal de corte; T3 - DPIC - depois do ponto ideal de corte. Verificou-se que para a produção de biomassa verde no corte obteve média significativa de 39.761,9 toneladas de massa verde por hectare, enquanto na rebrota foi de 53.571,42. Após os cortes das rebrotas (segundo corte), comparando-se a produção de biomassa verde nos três blocos observa-se que foram superiores em relação primeiro corte. Entretanto, o bloco 2 (PIC) da rebrota obteve maior produção com $60.714,28^{\mathrm{t}}$ quando comparado aos blocos 1 e 3 com produção de 54,285,71 ${ }^{\mathrm{t}}$ e 45.714,28 . Conclui-se que o aumento da idade de corte reduziu o teor de proteína bruta em relação a massa in natura, e causou aumento no teor de matéria seca tanto da forragem in natura quanto da silagem.
\end{abstract}

Palavras-chave: Conservação de forragem; Forrageira; Produção vegetal.

\begin{abstract}
The objective of this study was to evaluate the chemical characteristics of forage sorlum silage at different cutting frequencies. The research was conducted in the experimental sector at the Faculty of Technology of São Paulo in the premises of FATEC of Presidente Prudente-SP. The variety of forage sorb (Hybrid Silageiro Podium safra 2019 Biomatrix) was used. The experimental design used was in randomized blocks, with three subdivided plots, with four replications. The treatments were: T1 - APIC - before the ideal cut-off point; T2 - PIC - ideal cut-off point; T3 - DPIC - after the ideal cut-off point. It was verified that for the production of green biomass in the cut obtained a significant average of $39,761.9$ tons of green mass per hectare, while in the regrowth it was 53,571.42. After the cuts of the rebrotas (second cut), comparing the production of green biomass in the three blocks, it was observed that they were higher in relation to the first cut. However, block 2 (PIC) of the regrowth obtained higher production with 60,714.28t when compared to blocks 1 and 3 with production of 54,285.71t and 45,714.28t. It was concluded that the increase in the cutting age reduced the crude protein content in relation to the raw mass, and caused an increase in the dry matter content of both in natura forage and silage.
\end{abstract}

Keywords: Forage conservation; Forage, Plant production.

\section{Resumen}

El objetivo de este estudio fue evaluar las características químicas del ensilaje de sorlum forrajeo a diferentes frecuencias de corte. La investigación fue realizada en el sector experimental en la Facultad de Tecnología de São Paulo en las instalaciones de FATEC de Presidente Prudente-SP. Se utilizó la variedad de forraje sorb (Hybrid 
Silageiro Podium safra 2019 Biomatrix). El diseño experimental utilizado fue en bloques aleatorios, con tres gráficas subdivididas, con cuatro replicaciones. Los tratamientos fueron: T1 - APIC - antes del punto de corte ideal; T2 - PIC punto de corte ideal; T3 - DPIC - después del punto de corte ideal. Se verificó que para la producción de biomasa verde en el corte se obtuvo un promedio significativo de 39.761,9 toneladas de masa verde por hectárea, mientras que en el rebrote fue de 53.571,42. Tras los cortes de las rebrotas (segundo corte), comparando la producción de biomasa verde en los tres bloques, se observó que eran mayores en relación al primer corte. Sin embargo, el bloque 2 (PIC) del rebrote obtuvo una mayor producción con 60,714.28t en comparación con los bloques 1 y 3 con una producción de $54,285.71 \mathrm{t}$ y 45,714.28t. Se concluyó que el aumento en la edad de corte redujo el contenido de proteína cruda en relación con la masa cruda, y causó un aumento en el contenido de materia seca tanto del forraje in natura como del ensilaje.

Palabras clave: Conservación del forraje; Forraje, Producción vegetal.

\section{Introdução}

A planta de sorgo pode ser utilizada tanto para produção de grãos como de forragem para pastejo ou conservação na forma de silagem ou feno. É uma cultura altamente produtiva, com elevado valor nutritivo (Pinho et al., 2006) e adaptável a diferentes condições edafoclimáticas. A tolerância à seca é uma característica que evidencia sua importância (Borrell et al., 2014; Johnson et al., 2014; Liu et al., 2014) em regiões áridas como a África, o sul dos Estados Unidos (Paterson et al., 2009) e nos cerrados brasileiros.

O sorgo como planta forrageira é muito utilizado como silagem na alimentação de bovinos por possuir alto teor nutritivo, altos rendimentos de massa seca por unidade de área e características fenotípicas favoráveis ao manejo, plantio, colheita e armazenamento (Wall \& Ross,1975). Para Cruz et al. (2001) o sorgo constitui cultura adequada para o processo de ensilagem por sua facilidade de cultivo, alto rendimento e pela excelente qualidade da silagem produzida, além de dispensar o uso de aditivos como forma de melhorar e estimular a fermentação

Hoje, o sorgo tem apresentado aumentos significativos na sua utilização como forragem, o que é atribuído ao uso da diversidade genética no desenvolvimento de novas cultivares adaptadas aos diferentes sistemas de manejo no país, apresentando maior produtividade e melhor qualidade do produto (Embrapa Milho e Sorgo, 2009). Dentre os tipos de sorgo, o sorgo forrageiro é um dos que mais cresce no país. Em 2012/2013, plantou-se no Brasil em torno de 5000.000 ha de sorgo destinados à produção de forragem, passando a ter importância estratégica no abastecimento de grãos e forragem do país (CONAB, 2013).

Atualmente, a safra 2016/2017, a área plantada de sorgo forrageiro no Brasil é 367.275 ha $^{-1}$ (APPS, 2017). Este grupo está destinado à produção de forragem a fim de suprir as necessidades de alimentação animal na época de escassez, garantindo oferta de alimento e redução de custos (Parrella et al., 2014). A produção mundial de sorgo foi estimada em cerca de 61,4 milhões de toneladas, sendo que a brasileira contribuiu com mais de 2 milhões de toneladas (FAOSTAT - FAO, 2013), tendo uma área plantada de sorgo granífero de 802,3 mil hectares (CONAB, 2014).

Portanto, objetivou-se avaliar a produção de biomassa verde do corte e da rebrota e as características químicas in natura e da silagem do sorgo forrageiro em diferentes frequências de corte.

\section{Material e Métodos}

A pesquisa foi conduzida no setor experimental na Faculdade de Tecnologia de São Paulo nas dependências da FATEC de Presidente Prudente, localizada no extremo oeste do estado de São Paulo, situada nas coordenadas geográficas com latitude $22^{\circ} 07^{\prime} 04^{\prime \prime} \mathrm{S}$ e longitude $51^{\circ} 22^{\prime} 57^{\prime \prime} \mathrm{W}$, com altitude de 472 metros acima do nível do mar e temperatura entre $15^{\circ} \mathrm{C}$ e $32{ }^{\circ} \mathrm{C}$, com média de $21,6^{\circ} \mathrm{C}$ e uma pluviosidade média anual de $1207 \mathrm{~mm}$.

Utilizou-se a variedade de sorgo forrageiro (Híbrido silageiro Podium safra 2019 Biomatrix). A área delimita foi de $14 \mathrm{~m}$ comprimento por $5 \mathrm{~m}$ de largura perfazendo uma área total de $70 \mathrm{~m}^{2}$. A planta do sorgo é porte alto $(2,50 \mathrm{~A} 2,80 \mathrm{~m})$ ideal 
para ensilagem com recomendação de uso planta inteira aos 100 a 110 dias após o plantio, proporcionando uma silagem com média de PB 8,5\% NDT 68\% e FDN 55\%.

O cultivo do sorgo foi sob condições de irrigação por aspersão quando necessário, com as parcelas experimentais dispostas perpendicularmente à linha de aspersores. O turno de rega fora de horários de acionamento (Irrigação) às 06:45 06:49; 10:41 - 10:45; 14:53 - 14:57; 17:00 - 17:06 e 20:00 - 20:04, iniciadas após a semeadura e suspensas apenas durante período chuvoso.

O solo da área experimental apresentou os seguintes atributos químicos (perfil de 0 a $20 \mathrm{~cm}$ ): $\mathrm{pH}\left(\mathrm{CaCl}_{2}\right)$ : 6,7; matéria orgânica: $16\left(\mathrm{~g} \mathrm{dm}^{-3}\right) ; \mathrm{P}_{\text {(resina) }}$ : $402\left(\mathrm{mg} \mathrm{dm}^{-3}\right) ; \mathrm{Al}^{3+}: 0 ; \mathrm{H}+\mathrm{Al}: 14\left(\mathrm{mmol}_{\mathrm{c}} \mathrm{dm}^{-3}\right) ; \mathrm{K}: 3,1\left(\mathrm{mmol}_{\mathrm{c}} \mathrm{dm}^{-3}\right) ; \mathrm{Ca}: 235\left(\mathrm{mmol}_{\mathrm{c}} \mathrm{dm}^{-3}\right) ; \mathrm{Mg}$ : $73\left(\right.$ mmol $\left._{c} \mathrm{dm}^{-3}\right)$; saturação de bases: 311 e CTC: 325 . Procedeu-se o cultivo sem considerar realizar correção do solo, no entanto, efetuou-se a adubação de cobertura com superfosfato simples (18\% de $\left.\mathrm{P}_{2} \mathrm{O}_{5}\right)$ na proporção de $500 \mathrm{~kg}$ por ha-1.

Efetuou-se o plantio em sistema de cultivo mínimo e a área foi sulcada no espaçamento de um metro entre linhas. Em seguida, aplicou-se adubação manual nos sulcos de plantio, utilizando-se $20 \mathrm{~g}$ de superfosfato simples (4/14/8) por metro. Posteriormente, foram distribuídas sementes de sorgo, com o objetivo de obtenção de uma população de 200.000 plantas por hectare. O desbaste foi efetuado aos sete dias após a emergência das plântulas deixando-se o equivalente a vinte plantas por metro.

Optou-se em realizar todos os cortes (primeiro e segundo) na altura de $20 \mathrm{~cm}$ do solo. O primeiro corte do sorgo foi realizado, após 130 dias da germinação, quando as plantas apresentavam panículas completamente abertas com intervalos de dez dias entre os cortes, num total de três cortes. Aos cinquenta dias de intervalo do último corte ocorreu o primeiro corte da rebrota com intervalo de dez dias, num total de três cortes.

O delineamento experimental utilizado foi em blocos ao acaso, com três parcelas subdivididas, com quatro repetições. As parcelas experimentais foram constituídas por 4 fileiras de 14 metros, espaçadas de $1 \mathrm{~m}$. Os tratamentos foram: T1 - APIC - antes do ponto ideal de corte; T2 - PIC - ponto ideal de corte; T3 - DPIC - depois do ponto ideal de corte. A análise estatística foi no software SASM-Agri.

\section{Resultados e Discussão}

A germinação do sorgo ocorreu entre o $5^{\circ}$ e $7^{\circ}$ dia, após o plantio, notou-se que houve diferença significativa na velocidade de crescimento inicial das plântulas de sorgo. A emergência da panícula iniciou-se aos três meses, após o plantio, porém a emergência total ocorreu aos 120 dias.

A emergência da panícula do sorgo iniciou-se aos três meses, após o plantio, porém a emergência total ocorreu aos 120 após o plantio. Nas Figuras (1, 2 e 3) estão ilustradas as etapas do desenvolvimento do sorgo em função dos dias após o plantio. 
Research, Society and Development, v. 10, n. 13, e542101321728, 2021

(CC BY 4.0) | ISSN 2525-3409 | DOI: http://dx.doi.org/10.33448/rsd-v10i13.21728

Figura 1. Sorgo forrageiro 60 dias, após o plantio.

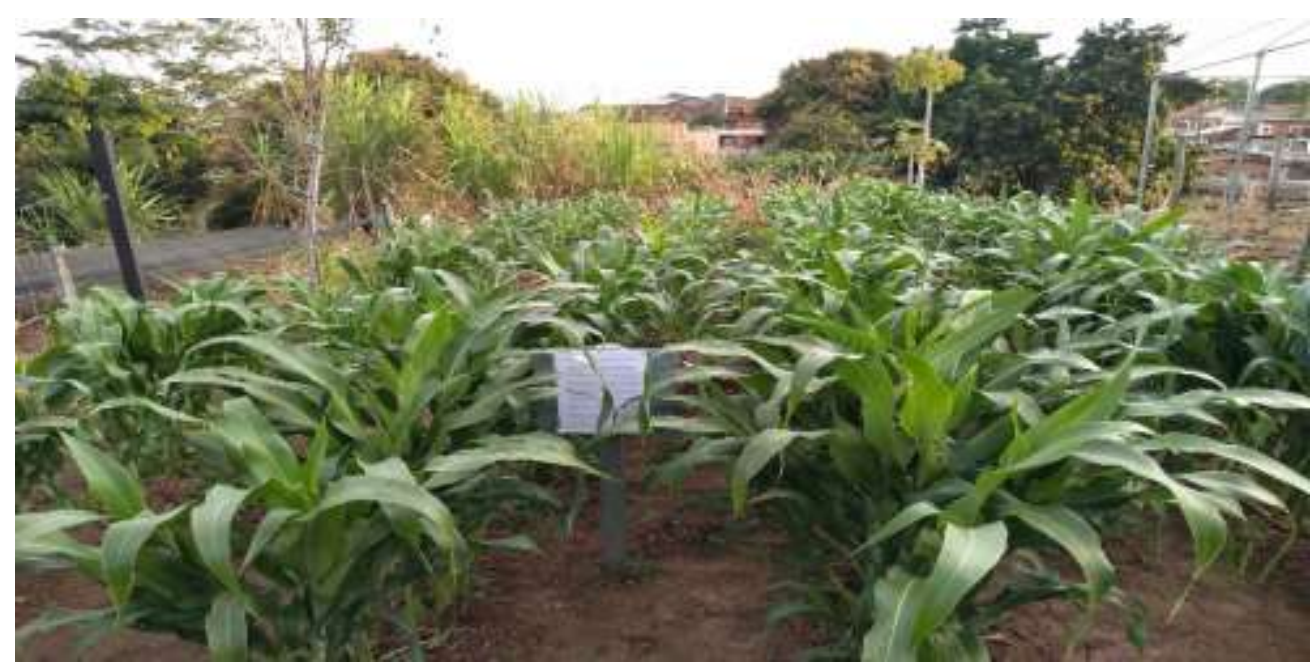

Fonte: Autores (2020).

Figura 2. Sorgo forrageiro 90 dias, após o plantio.

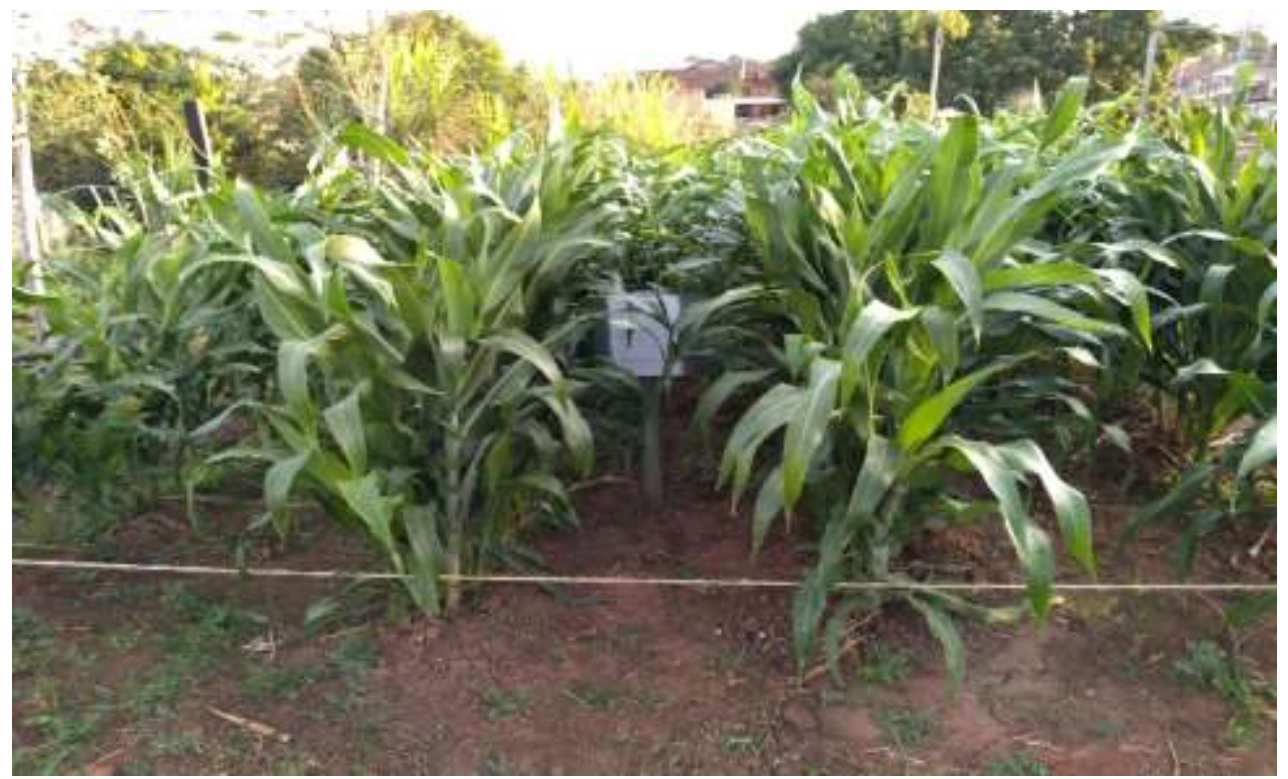

Fonte: Autores (2020). 


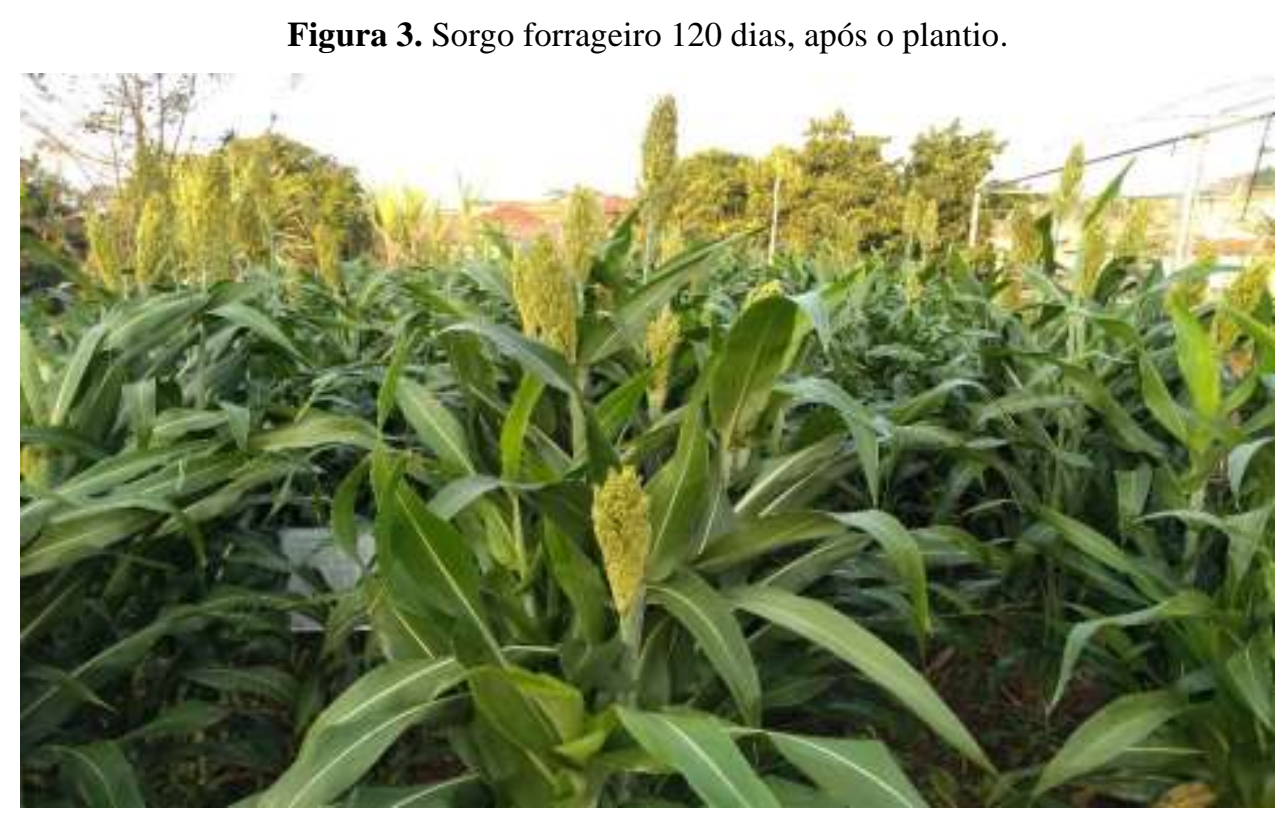

Fonte: Autores (2020).

Quanto à altura das plantas verificou-se que o crescimento foi retardado e as planta emitiram perfilho (brotos) laterais, pois de acordo com as recomendações sobre a cultivar testada nessa pesquisa as plantas não atingiram altura ideal. A altura das plantas $(\mathrm{cm})$ foi medida individualmente e retirada a média de $1,70 \mathrm{~cm}$, a partir da superfície do solo, até a panícula.

A redução da altura de cultivares de grande porte é relevante, pois acarreta diminuição dos custos de produção devido ao decréscimo de mão-de-obra utilizada durante o corte e por perdas no campo (Molina et al., 2000; Corrêa et al., 1996). De igual modo, a produtividade de matéria seca de sorgo forrageiro, está geralmente correlacionada com a altura da planta. O potencial de produção de matéria seca aumenta com a altura da planta (Rodrigues, 2007).

Por sua vez, verificou-se que para a produção de biomassa verde no corte obteve média significativa de 39.761,9 toneladas de massa verde por hectare, enquanto na rebrota foi de 53.571,42, valores esses significativos representados na Tabela 1. Miranda e Pereira (2001) afirmam que, a produção de massa verde dos híbridos é alta, variando de 50 a 70 t/há no primeiro corte; eles têm boa rebrota, colhendo-se de 30 a $70 \%$ no segundo corte, dependendo da temperatura, da disponibilidade de água, da fertilidade do solo e adubação. Enquanto, Mateus \& Crucil (2004), afirmam que a produção de matéria seca da parte aérea diminuiu à medida que o plantio foi mais tardio verificando-se valores de 32 a $4,6 \mathrm{t} \mathrm{ha}^{-1}$, respectivamente, nos plantios de setembro e abril.

Tabela 1. Produtividade de Biomassa Verde de Sorgo Forrageiro em função do bloco.

\begin{tabular}{|c|c|c|c|c|}
\hline Variáveis & $\begin{array}{l}\text { Bloco1 } \\
\text { APIC }\end{array}$ & $\begin{array}{c}\text { Bloco } 2 \\
\text { PIC }\end{array}$ & $\begin{array}{r}\text { Bloco3 } \\
\text { DPIC }\end{array}$ & Média \\
\hline Produção corte/bloco & $60 \mathrm{~kg}$ & $55 \mathrm{~kg}$ & $52 \mathrm{~kg}$ & - \\
\hline Produção corte/bloco/ha ${ }^{1}$ & $42.857,14 \mathrm{t}^{2}$ & $39.285,71 \mathrm{t}^{2}$ & $37.142,85 \mathrm{t}^{2}$ & $39.761,9 t^{2}$ \\
\hline Produção corte da rebrota/bloco & $76 \mathrm{~kg}$ & $85 \mathrm{~kg}$ & $64 \mathrm{~kg}$ & - \\
\hline Produção rebrota/bloco/ha ${ }^{1}$ & $54.285,71 \mathrm{t}^{2}$ & $60.714,28 \mathrm{t}^{2}$ & $45.714,28 \mathrm{t}^{2}$ & $53.571,42 \mathrm{t}^{2}$ \\
\hline
\end{tabular}

${ }^{1}$ ha $=$ hectare; ${ }^{2} \mathrm{t}=$ tonelada; APIC $=$ antes do período ideal de corte PIC $=$ período ideal de corte DPIC $=$ depois do período ideal de corte.

Fonte: Dados coletados pelos autores (2021). 
Após os cortes das rebrotas (segundo corte), comparando-se a produção de biomassa verde nos três blocos observa-se que foram superiores em relação primeiro corte. Entretanto, o bloco 2 (PIC) da rebrota obteve maior produção com $60.714,28{ }^{t}$ quando comparado aos blocos 1 e 3 com produção de 54,285,71 ${ }^{\mathrm{t}}$ e 45.714,28 $8^{\mathrm{t}}$ respectivamente (Figura 1). Para Rezende et al. (2011) a produção de forragem da rebrota do sorgo é influenciada pelo sistema de cultivo, com destaque positivo para o sistema consorciado.

Figura 1. Produção de sorgo em função do corte e da rebrota.

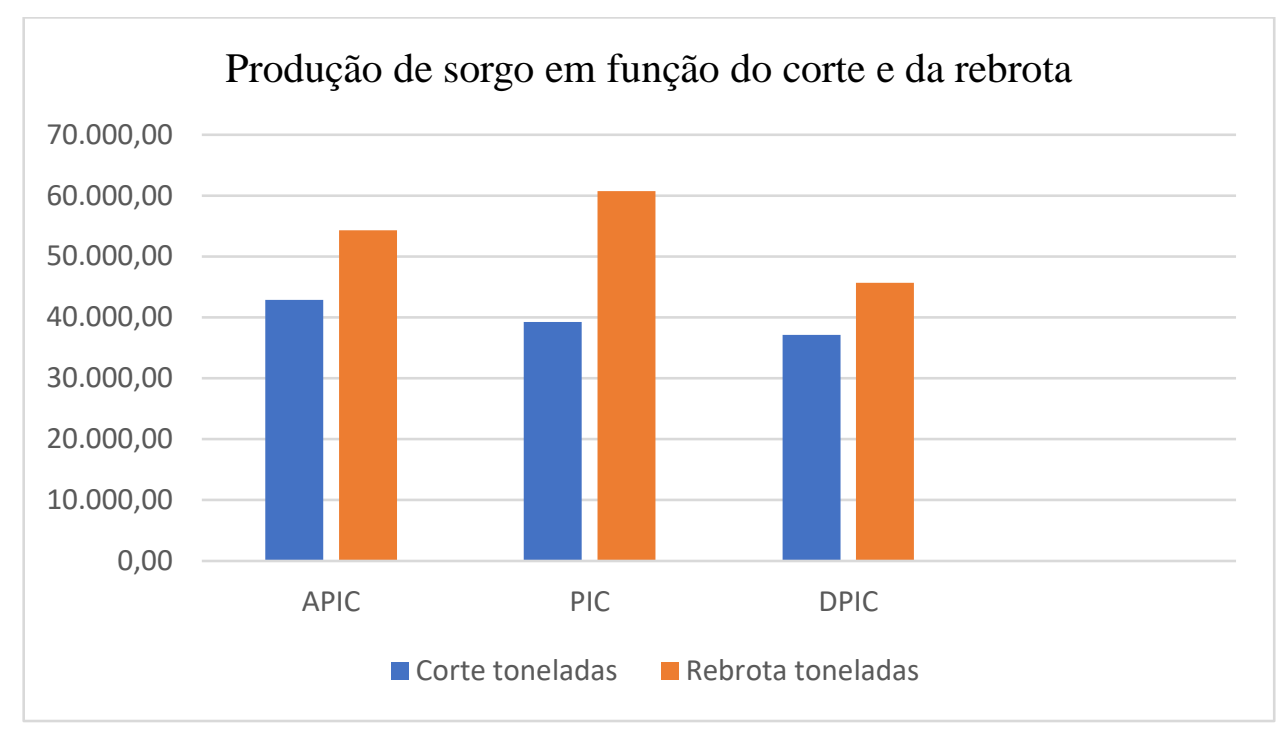

Fonte: Autores (2021).

A produtividade também varia com a idade de corte e da rebrota. Trabalhos desenvolvidos com capim elefante, por Lavezzo et al (1990), foi constatado que a produtividade variou de 70,3 e 83,2 toneladas de matéria verde (MV) por ha quando cortado com 60 dias de idade, para 77,2 e 97,2 toneladas de MV por ha quando cortado com 75 dias de idade. Assim para se estabelecer a idade de corte ideal tem-se que levar em consideração não só a composição químico-bromatológica, mas também a produtividade.

Os resultados da análise química do sorgo são apresentados em relação ao parâmetro de valores de Matéria Seca (MS), Proteína Bruta (PB), Fibra Bruta (FB), Fibra em Detergente Neutro (FDN), Fibra em Detergente Ácido (FDA) e Nutrientes Digestíveis Totais (NDT) obtiveram respectivamente valores descritos na (Tabela 2).

Tabela 2. Composição químico-bromatológica de sorgo in natura.

\begin{tabular}{lccc}
\hline Parâmetros & $\begin{array}{c}\text { Corte/APIC } \\
120 \text { dias }\end{array}$ & $\begin{array}{c}\text { Corte/PIC } \\
130 \text { dias }\end{array}$ & $\begin{array}{c}\text { Corte/DPIC } \\
\text { 140 dias }\end{array}$ \\
\hline Matéria seca & 22,80 & 24,44 & 30,62 \\
Proteína bruta & 13,62 & 14,03 & 9,36 \\
Extrato Etéreo & 1,54 & 1,15 & 2,29 \\
Fibra em detergente ácido & 50,65 & 40,51 & 33,89 \\
Fibra e detergente neutro & 70,75 & 70,54 & 56,51 \\
Nutrientes totais digestíveis & 49,45 & 57,34 & $62, \mathbf{5 0}$ \\
\hline
\end{tabular}

APIC $=$ antes do período ideal de corte PIC $=$ período ideal de corte $;$ DPIC $=$ depois do período ideal de corte.

Fonte: Dados coletados pelos autores (2021). 
A idade de corte teve efeito sobre a MS da forragem in natura de sorgo, sendo que o maior valor de MS foi encontrado na planta com 140 dias de idade, como pode ser observado na Tabela 2. Foi constatado, também, que a elevação da idade de corte proporcionou aumentos lineares nos teores de MS das silagens, que variaram de 22,80\% a 24,44\%, quando cortadas entre as idades de 120 a 130 dias.

É importante salientar que os níveis de MS da forragem in natura de sorgo com 120 e 130 dias estão abaixo do recomendado para produção de silagem, que segundo McDonald (1981) o teor de matéria seca da forragem deve estar entre 30,0 e $35,0 \%$, para que o processo fermentativo ocorra de forma satisfatória.

Capelle et al. (2006), constataram que a MS da planta de sorgo aumentou com o adiamento da colheita, variando de $22,89 \%$ quando cortado entre 61 e 90 dias de idade, 34,61\% quando cortado entre 91 e 120 dias e quando o corte foi realizado entre 121 a 150 dias a planta apresentou MS de 43,07\%.

Tabela 3. Composição químico-bromatológica de sorgo in natura.

\begin{tabular}{lccc}
\hline Parâmetros & $\begin{array}{r}\text { Corte/APIC } \\
120 \text { dias }\end{array}$ & $\begin{array}{c}\text { Corte/PIC } \\
130 \text { dias }\end{array}$ & $\begin{array}{c}\text { Corte/DPIC } \\
140 \text { dias }\end{array}$ \\
\hline Matéria seca & 19,03 & 22,50 & 24,67 \\
Proteína bruta & 12,68 & 13,19 & 12,64 \\
Extrato Etéreo & 2,34 & 2,19 & 2,25 \\
Fibra em detergente ácido & 38,08 & 35,92 & 33,11 \\
Fibra e detergente neutro & 67,02 & 61,89 & 58,83 \\
Nutrientes totais digestíveis & 59,24 & 60,92 & 63,11 \\
\hline
\end{tabular}

APIC $=$ antes do período ideal de corte PIC $=$ período ideal de corte DPIC $=$ depois do período ideal de corte.

Fonte: Dados coletados pelos autores (2021).

De acordo com Pitt et al. (1991), valores abaixo de 28\% de MS aumentam as perdas por efluentes, além de favorecer a atuação de microrganismos indesejáveis na massa ensilada.

Alvarenga (1993) não encontrou diferenças significativas para o consumo de matéria seca de silagens de sorgo colhidas em três diferentes épocas, com teores de matéria seca variando de 26,89\% a 29,10\%.

Zago (1991) observou que o teor de matéria seca do sorgo AG2002, de colmo suculento foi de 21,1; 24,9; 30,9 e 29,3 $\%$ de matéria seca; e de 29,1; 33,4; 38,7 e 48,9 \% de matéria seca para o AG2005E, de colmo seco, para os estádios de grãos leitosos, pastosos, farináceos e duros, respectivamente.

Pereira et al., (2007) com 56 dias de aberturas dos silos encontraram MS 30,89; PB 5,15 com vinte e oito dias.

\section{Conclusão}

Conclui-se que o aumento da idade de corte reduziu o teor de proteína bruta em relação a massa in natura, e causou aumento no teor de matéria seca tanto da forragem in natura quanto da silagem.

\section{Referências}

Alvarenga, M. C. V. (1993). Consumo e digestibilidade aparente de silagens de sorgo (Sorghum vulgare Pers) em três momentos de corte e dois tamanhos de partículas em carneiros. 41f. Dissertação (Mestrado em zootecnia) - Escola de Veterinária, UFMG. Belo Horizonte. 
APPS. (2017). Evolução da área e produção de sorgo no Brasil. < www.http://apps.agr.br/Site/Home.

Borrell, A. K., Mullet, J. E., Jaeggli, B. G., Van Oosterom, E. J., Hammer, G. L., Klein, P. E. \& Jordan, D. R. (2014). Drought adaptation of stay-green sorghum is associated with canopy development, leaf anatomy, root growth, and water uptake. Journal of Experimental Botany, 13 jun.

Capelle, E. R., Rocha Junior, V. R., Magalhães, K. A. \& Valadares Filho, S. C. (2006) Tabelas brasileiras de composição de alimentos para bovinos. Viçosa: Ed. UFV.

CONAB. (2014). Acompanhamento da Safra Brasileira de Grãos. Observatório Agrícola, 1(2).

CONAB. (2013). Conjuntura mensal do sorgo. Brasília.

Corrêa, C. E. S. (1996). Qualidade das silagens de três híbridos de sorgo (Sorghum bicolor L.) em diferentes estádios de maturação. Belo Horizonte, 121p. (Mestrado- Escola de Veterinária, UFMG.

EMBRAPA. (2008) Cultivo do sorgo, Brasília.

FAOSTAT - FAO. (2013) Crops - Sorghum.

Stephanie M Johnson, S. M., Lim, F. L., Finkler, A., Fromn, H., Slabas, A. R. \& Knight, M. K. (2014). Transcriptomic analysis of Sorghum bicolor responding to combined heat and drought stress. BMC genomics, 15, 456.

Lavezzo, W. Lavezzo, O. E. N. M., Bonasssi, I. \& A., Basso, L. C. (1990) Efeitos do emurchecimento, formol e ácido fórmico e solução de "VIHER” sobre a qualidade de silagens de capim-elefante, cultivares Mineiros e Vruckwona. Pesquisa Agropecuária Brasileira, 25(1),. $125-134$.

Liu, P., Yin, L., Deng, X., Wang, S., Tanaka, K. \& Zhang, S. (2014). Aquaporin-mediated increase in root hydraulic conductance is involved in siliconinduced improved root water uptake under Osmotic stress in Sorghum bicolor L. Journal of experimental botany, 65(17), 4747-56.

Mcdonald, P. (1981). The biochemistry of silage. New York: John Willey \& Sons. 226p.

Mateus, G. P. \& Crucil, C. A. C. (2004). Desenvolvimento e produtividade de grãos do sorgo de Guiné "Gigante" em função da época de plantio. Revista Científica, 32(2),.164-170.

Miranda, J. E. C. \& Pereira, J. R. (2001). Instrução técnica para o produto de leite. Embrapa Gado de Leite.

Molina, L., Gonçalves, L. C., Rodriguez, N. M., Rodrigues, J.A.S. Ferreira, J.J. \& Ferreira, V. C. P. (2000). Avaliação agronômica de seis híbridos de sorgo (Sorghum bicolor (L.) Moench). Arquivo Brasileiro de Medicina Veterinária e Zootecnia, 52, 385-390.

Parente, H. N., Silva Júnior, O. R. da, Bandeira, J. R., Parente, M. O. M., Rosane Cláudia Rodrigues, R. C., \& Rocha, K. S. (2014). Produtividade do sorgo forrageiro em função de quantidades crescentes de adubação fosfatada e nitrogenada. Revista Trópica-Ciências Agrárias e Biológicas, 08. 1-10,

Pitt, R. E.; Muck, R. E. \& Pickering, N. B. (1991) A model of aerobic fungal growth in silage. 2. Aerobic stability. Grass and Forage Science, 46, 301-312.

Borém, A., Pimentel, L. \& Parellha, R. (2014). Sorgo do plantio à colheita. Editora UFV, 275p.

Paterson, A. H., John E. Bowers, J. E. \& Rokhsar, D. S. (2009). The Sorghum bicolor genome and the diversification of grasses. Nature, 457(7229), 551-6

Pereira, A. C., Silva, R. R. e, Gonçalves, L. C., Borges, A. L. C. C., Borges, I., Gomes, S. P., Rodrigues, J. A. S., Saliba, E.O. S., Ferreira, J. J. C., \& Silva J. J. da. (2007) Avaliação da silagem do híbrido de sorgo (sorghum bicolor (L.) Moench) BR 601 com aditivos 1 - PHA, nitrogênio amoniacal, matéria seca, proteína bruta e carboidratos solúveis. Revista Brasileira de Milho e Sorgo, 6(2), 211-222.

Pinho, R. G. V., Vasconcelos, R. C. de., Borges, I. D. \& Rezende, A. V. (2006). Influência da Altura de Corte das Plantas Características Agronômicas e valor nutritivo das silagens de milho e de diferentes tipos de sorgo. Revista Brasileira de Milho e Sorgo, 5(2), $266-279$.

Rezende, P. M., Alcantara, H. P. de., Passo, A. M. A. dos., Carvalho, E. R., Baliza, D. P. \& Oliveira, G. T. M. de. (2011). Rendimento forrageiro da rebrota do sorgo em sistema de produção consorciado com soja. Revista Brasileira Ciência Agrária, 6(2),.362-368.

Rodrigues, J. A. S. Produção e utilização de silagem de sorgo. (2007). In: IV Simpósio Mineiro de Nutrição de Gado de Leite. Belo Horizonte: Universidade Federal de Minas Gerais.

Wall, J. S. \& Ross, W. M. (1975). Production y usos del sorgo. Editorial Hemisfério Sul.

Zago, C. P. Cultura de sorgo para produção de silagem de alto valor nutritivo. (1991). In: Simpósio sobre nutrição de bovinos, Piracicaba,1991. Anais... Piracicaba, FEALQ,.169-217. 